\title{
Experimental analysis of composite bolted joints using digital image correlation
}

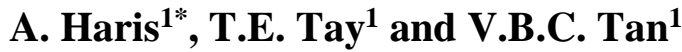 \\ ${ }^{1}$ Faculty of Engineering, National University of Singapore, \\ 9 Engineering Drive 1, Singapore 117576, Singapore \\ Email: mpeah@nus.edu.sg \\ Phone: +6565162237; Fax: +6567791459
}

\begin{abstract}
In this work, the application of the digital image correlation (DIC) technique to experimentally study progressive damage of single-lap composite bolted joints is explored. This technique is also used to provide surface strain fields and to analyse outof-plane phenomena of the joints due to the effect of laminate pattern, laminate thickness, fastener size, fastener type and bushing. The specimens were manufactured from plain weave carbon/epoxy composites. The bearing test was conducted in accordance with ASTM D5961/D5961M-13. The digital image correlation was performed using the commercial Vic-3D digital image correlation system. It was found that strain concentrations observed in the specimens can be used to identify full-field damage onset and to monitor damage progression during loading. Moreover, there is interaction between laminate pattern, laminate thickness, fastener size, fastener type and bushing on bearing strengths (ultimate and 2\% offset bearing strengths), surface strain concentrations and out-of-plane displacement. The DIC results can potentially be used to develop and accurately validate numerical models.
\end{abstract}

Keywords: Carbon/epoxy composite; bolted joint; bearing strength; digital image correlation; progressive damage.

\section{INTRODUCTION}

Aerospace and many other structures mostly involve joints. The need to use joints is because of manufacturing constraints and requirements related to the accessibility of the structure, quality control, part replacement and structural integrity assessment [1]. The joints tend to be the weakest part of the structure and thus may attribute to significant weight penalties [2]. Composite joints are more complicated than their metallic counterparts. The brittleness of most composite materials, the possibility of using highly orthotropic laminates to promote high stress concentrations, and the anisotropy in both strength and stiffness properties have to be taken into account when designing composite joints [1]. The joint efficiency and strength when using composites are much lower than those obtained in metallic materials, thereby hindering the widespread application of composites [3-6]. Digital image correlation for measuring displacement on solid surfaces was introduced in the 1980s by researchers at the University of South Carolina [7]. In recent years, this technique has been improved and optimized by many researchers [8] and has been applied to surface deformation measurement using images from Atomic Force Microscopy (AFM), Scanning Electron Microscopy (SEM) and X-ray micro tomography [9]. Quite recently, DIC has been used to experimentally study bonded and 
bolted joints of composite materials. Caminero et al. [10] employed DIC for on-line damage monitoring in composite laminates with an open hole and adhesively bonded patch repairs. They found that the location and extent of damage identified by DIC correlates well with X-ray results. Comer et al. [11] used DIC to detect damage progression in composite single lap bonded joints under quasi-static tensile loading and reported that a crack initiates at the corner of the lower laminate and propagates unstably in two directions: into the bond-line and along the edge of the laminate. The use of DIC for measuring peel and shear strains in the adhesive bondline of composite single-lap joints was studied by Kumar et al. [12] and it was found that higher strains occur at the edge of the bondline and lower strains occur at the centre. The cracks initiate at diagonally opposite interfaces near the joint edges and propagate with increasing load and finally shear at the centre causing a peel dominated failure or mode I failure.

Zhai et al. [13] employed DIC to study the effect of bolt hole clearance and bolt torque on composite bolted joints. They found that bolt-hole clearance increases the surface strain concentration and the out-of-plane deformation of the joints whereas bolt torque alleviates the surface strain concentration, though it has little effect on the out-ofplane deformation. Dhote et al. [14] used DIC to study the effect of liquid shim on composite bolted joints. It was found that the introduction of a shim layer amplifies secondary bending and the out-of-plane deformation of the joint and modifies the strain distribution, potentially leading to higher tensile strains in the laminates. Egan et al.[15] reported that experimental measures of secondary bending of composite bolted joints obtained using DIC provide good agreement with the numerical results. The current work focuses on the application of DIC to characterize composite single lap bolted joints due to the effect of laminate pattern, laminate thickness, fastener size, fastener type and bushing.

\section{METHODS AND MATERIALS}

\section{Materials}

The materials used in this study include a plain woven carbon fabric with an areal density of $197 \mathrm{~g} / \mathrm{m}^{2}$ and thickness of $0.26 \mathrm{~mm}$. The weave densities of the warp and weft are 12 ends/in and 12 picks/in, respectively. A diglycidyl ether of bisphenol A (DGEBA) epoxy resin with viscosity of $790 \mathrm{mPa} \cdot \mathrm{s}$ was used as the binding polymer/matrix. The composite laminates were made by hand lay-up and cured at room temperature for 16 hours, followed by post curing at $80^{\circ} \mathrm{C}$ for 315 minutes.

\section{Bearing Test}

The bearing test was performed following the ASTM D5961/D5961M-13 standard test method for the bearing response of polymer matrix composite laminates. This test method has four procedures: A, B, C, and D. Procedure B (single-shear tensile or compressive loading of a two-piece specimen) is used in this study because it has been extensively used for developing design allowable data. The test was conducted using an INSTRON 8501 universal testing machine equipped with a $100 \mathrm{kN}$ load cell. The crosshead speed of the machine was $2 \mathrm{~mm} / \mathrm{min}$. The digital 3D image correlation system VIC-3D was used as a virtual extensometer. Figure 1 shows the experimental setup used and specimen configuration for procedure B. Four cases are investigated: case \#1 (effect of laminate pattern), case \#2 (effect of laminate thickness), case \#3 (effect of fastener type and size), and case \#4 (effect of using bushing). In all cases five specimens were used for each test condition. All of them were sized to consistently induce bearing failure. The fasteners 
used were grade 12.9 high tensile bolts with a minimum yield strength of $1100 \mathrm{MPa}$ and a proof load of $970 \mathrm{MPa}$ (YFS brand). All bolts were tightened to a pre-defined torque with a torque wrench (Wera $7000 \mathrm{~A}$ ): $1.1 \mathrm{Nm}, 2.2 \mathrm{Nm}$, and $3.6 \mathrm{Nm}$ for the metric bolt diameter of $3 \mathrm{~mm}, 6 \mathrm{~mm}$, and $10 \mathrm{~mm}$, respectively. In all cases, no washer was used.

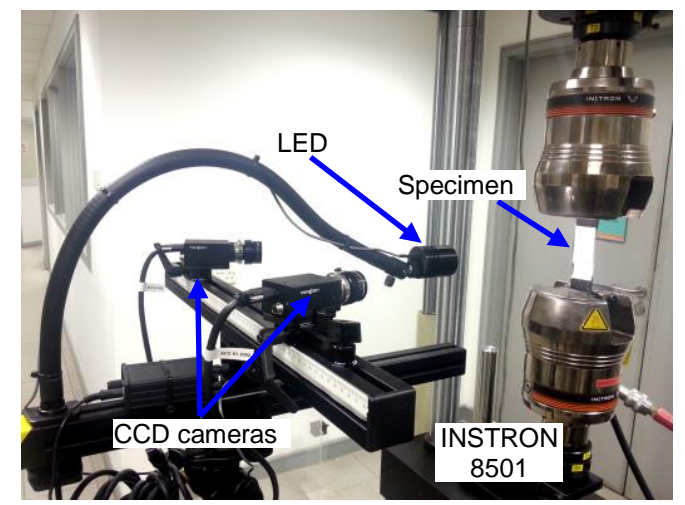

(a)
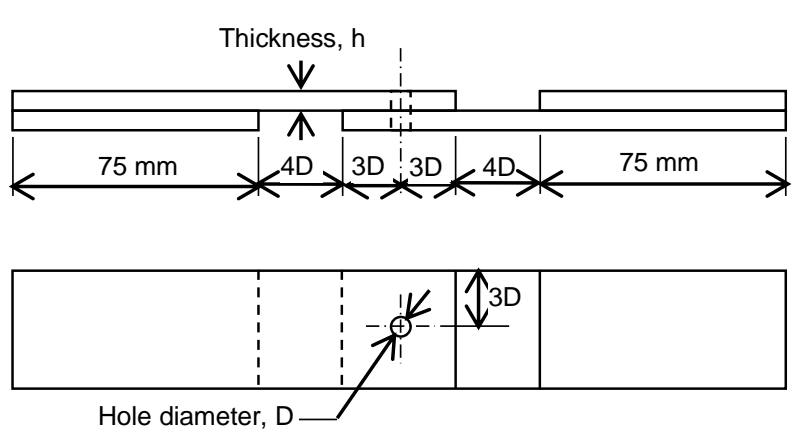

(b)

Figure 1. (a) Experimental setup for bearing test; (b) specimen geometry.

\section{Digital Image Correlation Test}

Digital image correlation was performed using the Vic-3D digital image correlation system from Correlated Solutions Inc. (CSI). The Vic-3D DIC apparatus consisted of <a> two 2.8 megapixel digital cameras (1928 x 1448 @ $26 \mathrm{fps}$ ) fitted with Schneider $35 \mathrm{~mm}$ optical lenses, $<\mathrm{b}>$ one LED lighting system with gooseneck positioning arms, and $<\mathrm{c}>\mathrm{a}$ computer complete with Vic-3D v7.0 image correlation software, Vic-2D image correlation software, and Vic-Snap LS image acquisition software. This can measure strains from 50 microstrain to $2000 \%$ strain and above. Nippon acrylic matt spray paint from an aerosol can was used to generate the speckle pattern. A white background was painted onto the specimen surface, followed by small black spray paint droplets that were randomly applied by spraying at a distance of approximately $300 \mathrm{~mm}$ from the specimen surface.

\section{RESULTS AND DISCUSSION}

\section{Progressive Damage}

The bearing failure mode of composite bolted joint results primarily from the compression and shear failures of the fibre and matrix [16]. A typical bearing load versus displacement curve for a single-lap composite bolted joint is presented in Figure 2. In general, the curve starts with a linear portion. The slope of this linear portion is called the bearing chord stiffness. Subsequently, an initiation of damage activates a non-linear part of the curve. After that, a bearing failure induces the load to drop slightly. Following this small load drop, the composite fastened joints can still carry an additional load causing increases again until the ultimate load is reached $[17,18]$. Axial strain (loading direction) and shear strain fields, and out-of-plane deformation of single-lap composite bolted joint obtained by the DIC technique at different applied bearing load levels are shown in Figures 3-5. From the strain contours, axial compressive strain concentration (Figure 3) and shear strain concentration (Figure 4) are observed in the bearing plane of the specimen which can be used to identify damage onset and progression during loading. It is obvious that the strain concentration becomes larger as the load level increases. The 
load drop after the ultimate load associated with excessive strain concentration is also observed. A similar phenomenon is evident for the out-of-plane displacement (Figure 5).
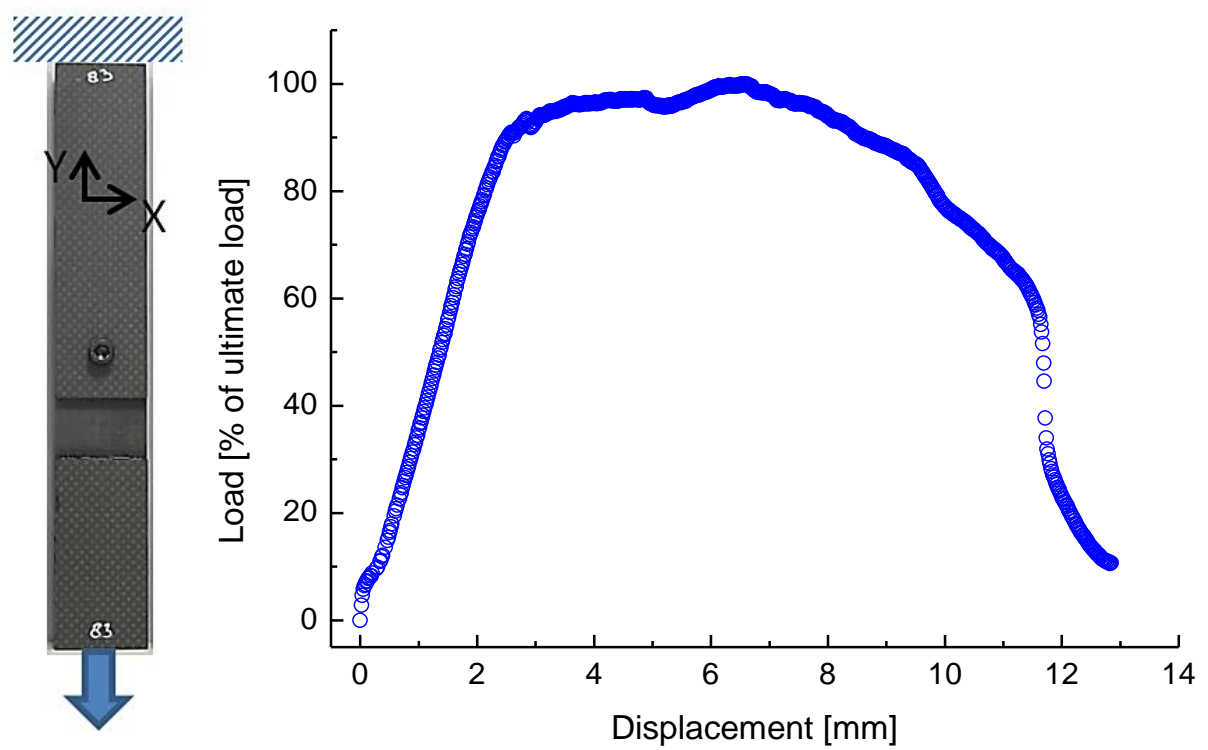

Figure 2. Typical bearing load versus displacement for single-lap composite bolted joint $\left(\mathrm{D}=6 \mathrm{~mm}\right.$, layup $=\left[0 /(45)_{2} / 0\right]_{2 \mathrm{sf}}, \mathrm{h}=3.83 \mathrm{~mm}$, ultimate load $\left.=11.85 \mathrm{kN}\right)$.
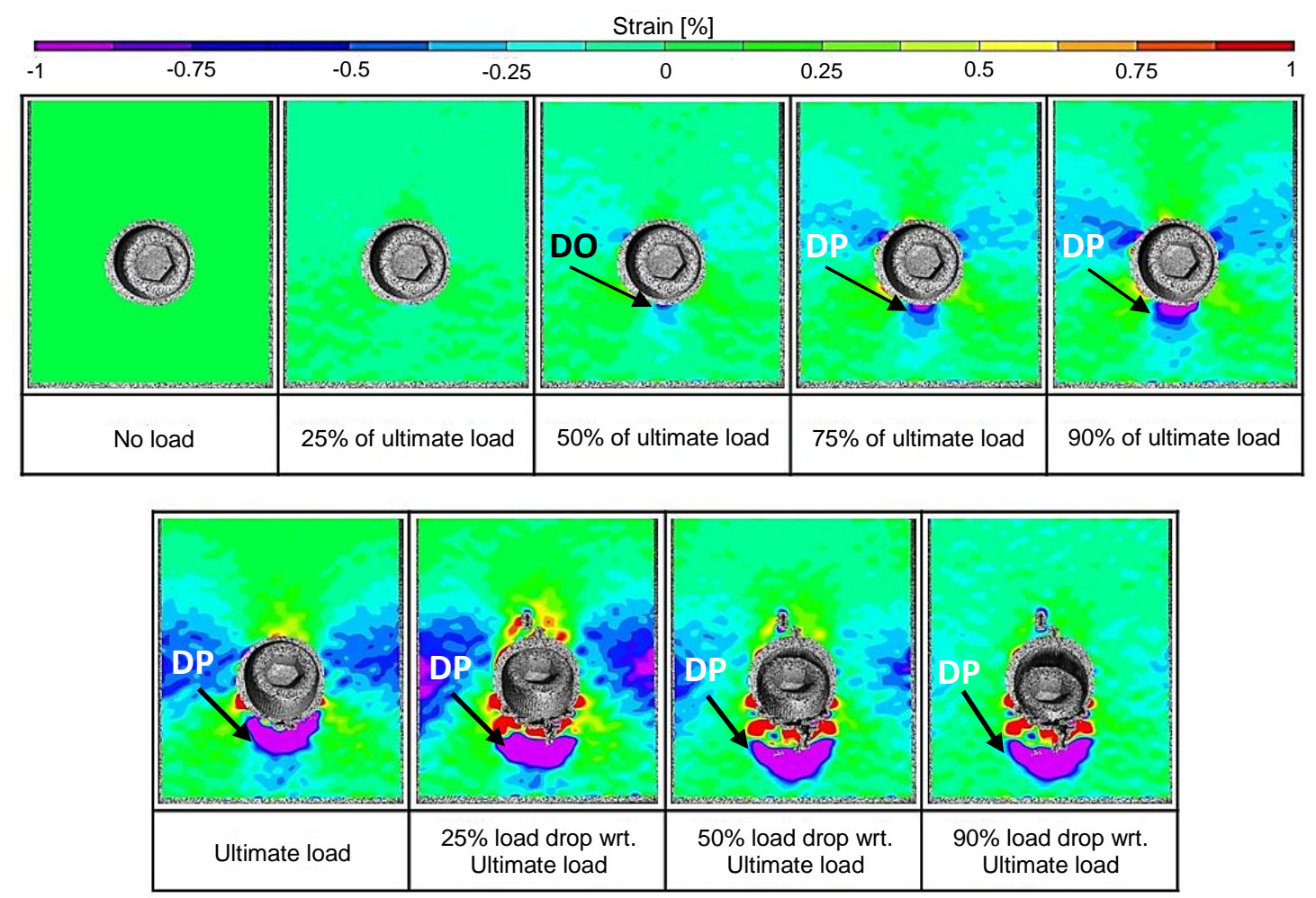

Figure 3. Axial strain $\varepsilon_{y}$ (loading direction) distribution as a function of bearing load level (DO: Damage Onset, DP: Damage Progression). 

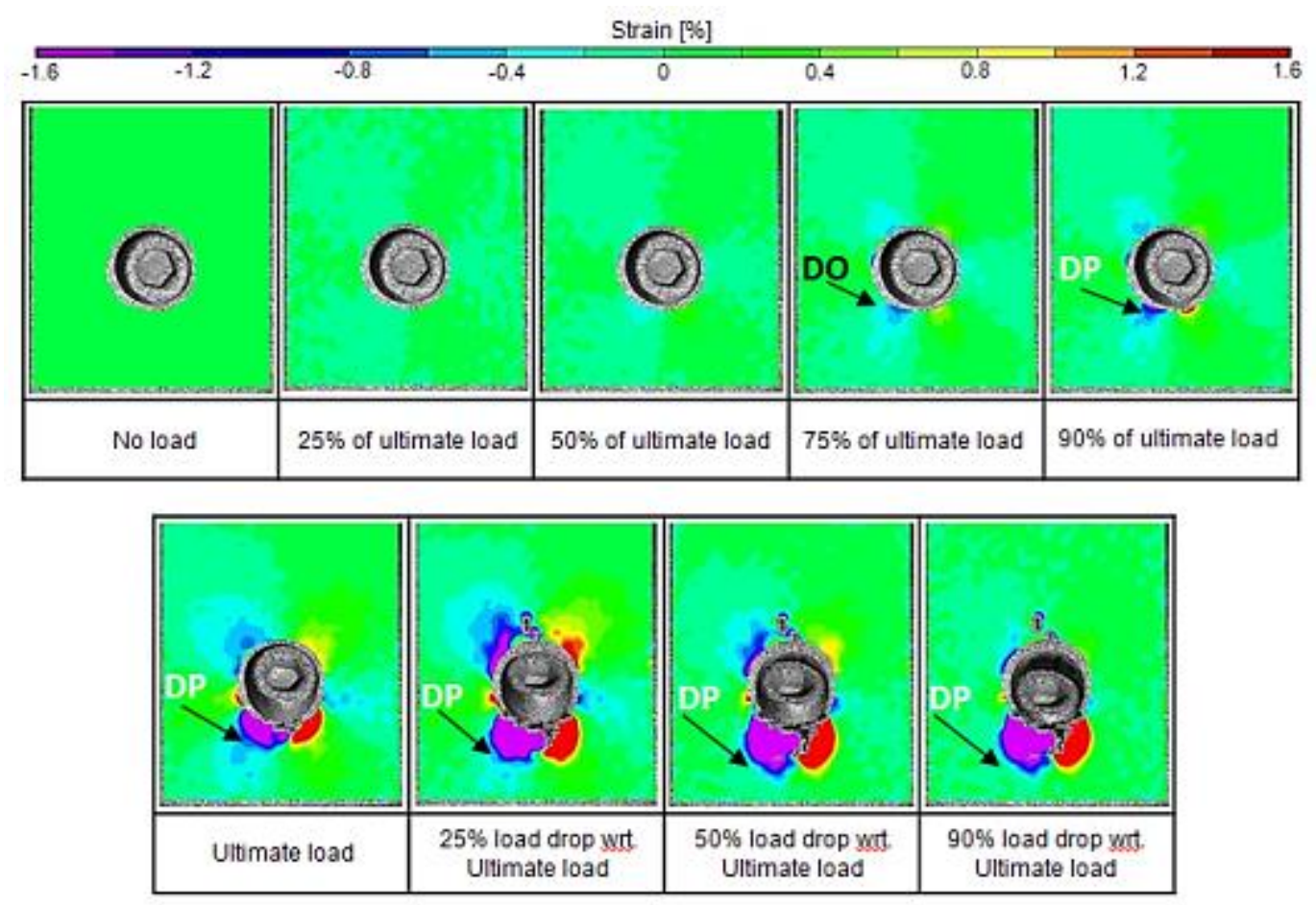

Figure 4. Shear strain $\varepsilon_{x y}$ distribution as a function of bearing load level.
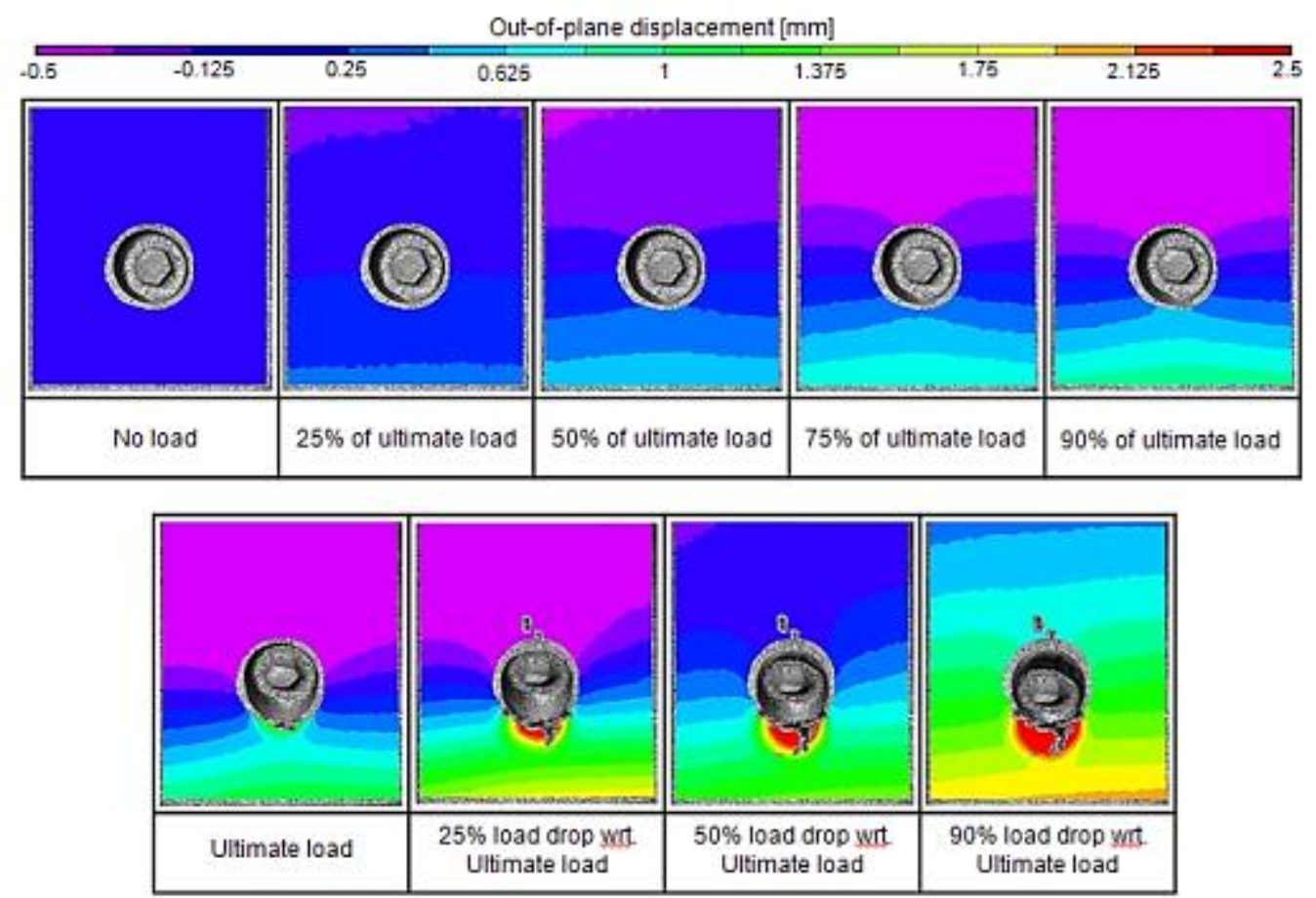

Figure 5. Out-of-plane deformation as a function of bearing load level.

\section{Effect of Laminate Pattern}

Five layup patterns made from combinations of 0-degree fabric plies and 45-degree fabric plies are considered: $0 \% 0$-degree fabric plies (100\% 45-degree fabric plies), $37.5 \% 0$ degree fabric plies (62.5\% 45-degree fabric plies), 50\% 0-degree fabric plies (50\% 45 - 
degree fabric plies = quasi isotropic), $62.5 \% 0$-degree fabric plies $(37.5 \% 45$-degree fabric plies), and 100\% 0-degree fabric plies (0\% 45-degree fabric plies). Figure 6 shows the effect of varying the percentage of 0-degree fabric plies (or 45-degree fabric plies) on ultimate and $2 \%$ offset bearing strengths. The laminate with $50 \% 0$-degree fabric (quasiisotropic) provides the highest offset and ultimate bearing strengths. Reducing the percentage of 0 -degree fabric plies below $50 \%$ or increasing it above $50 \%$ lessens the bearing strength. This result is consistent with previous results from other researchers showing that the general trend is that quasi-isotropic, or near quasi-isotropic laminates experience higher bearing strengths [4]. As shown in Figure 7, there is an obvious disparity between the strain contours obtained for the layup patterns tested. The quasi isotropic laminate has the smallest axial compressive strain concentration and shear strain concentration providing the best bearing performance. A large axial compressive strain concentration is induced in the bearing plane of the $0 \% 0$-degree fabric laminate whereas a large shear strain concentration is induced in the bearing plane of the $100 \% 0$-degree fabric laminate. This may explain why these two layup patterns have poor bearing strengths.

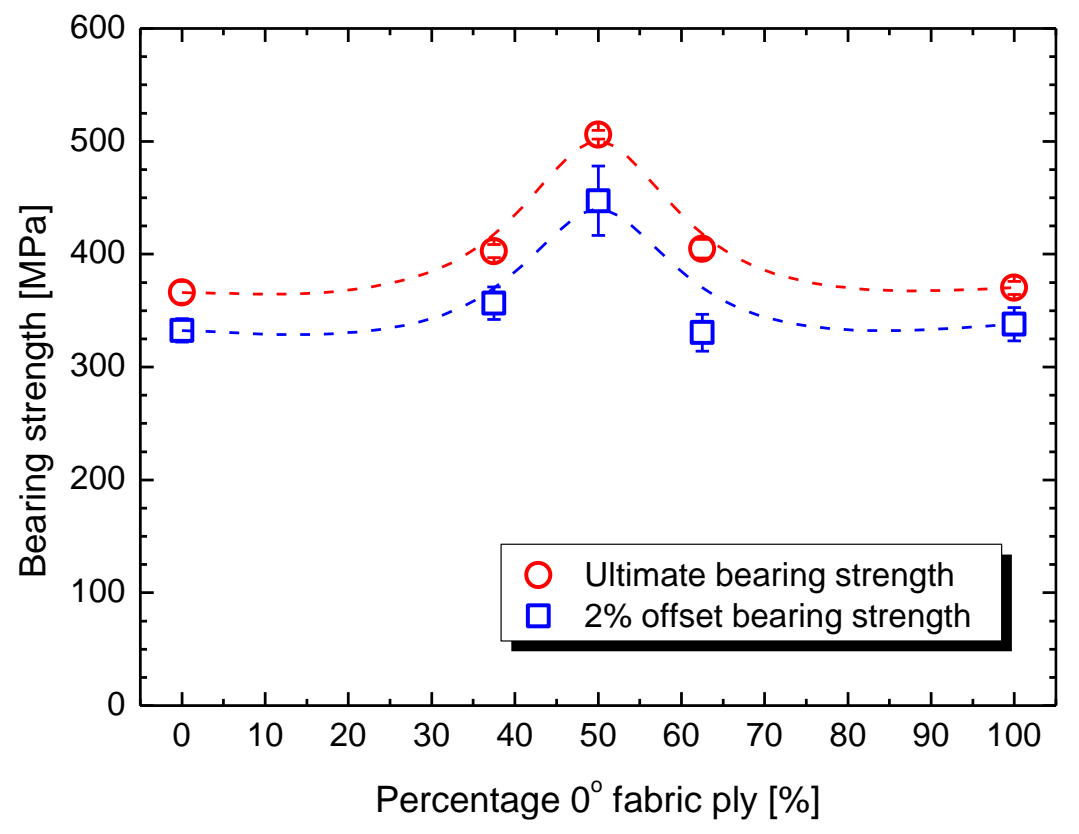

Figure 6. Effect of laminate pattern on $2 \%$ offset bearing strength and ultimate bearing strength $\left(\mathrm{D}=6 \mathrm{~mm}\right.$, layups $=[45]_{16 \mathrm{f}},\left[(45 / 0 / 45)_{2} / 45 / 0\right]_{\mathrm{sf}},\left[0 /(45)_{2} / 0\right]_{2 \mathrm{sf}},\left[(0 / 45 / 0)_{2} / 0 / 45\right]_{\mathrm{sf}}$, $\left.[0]_{16 f}\right)$.

\section{Effect of Laminate Thickness}

Three laminate thicknesses are studied: $2.10 \mathrm{~mm}$ ( 8 plies), $3.83 \mathrm{~mm}$ (16 plies) and 5.29 $\mathrm{mm}$ ( 24 plies). The effect of laminate thickness on the ultimate and $2 \%$ offset bearing strengths is given in Figure 8. It is seen clearly in the figure that both of the bearing strengths are influenced by the laminate thickness. The $\sim 4 \mathrm{~mm}$ thick laminate (16 plies) has the highest ultimate and offset bearing strengths. Collings [19] reported that the thickness effect on bearing strengths depends on the lateral constraint/clamping force applied to the bolts. Under low bolt preloads (between 0 to $6.8 \mathrm{Nm}$ ), the laminate with 18 plies ( 4 mm to $4.5 \mathrm{~mm}$ thick) exhibits the highest bearing strength. At higher bolt preloads, bearing strength decreases with increasing laminate thickness. 


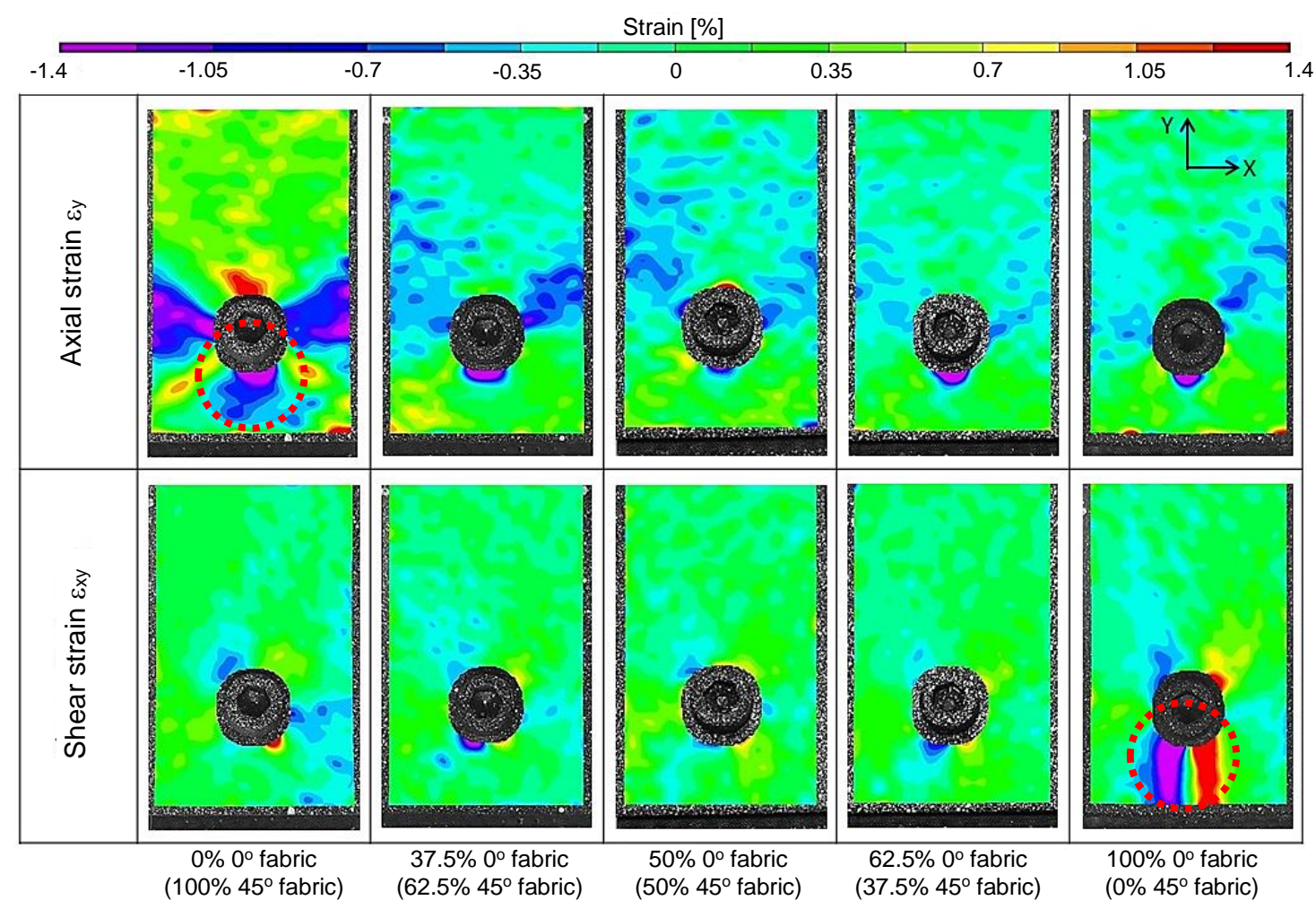

Figure 7. Axial strain $\varepsilon_{y}$ and shear strain $\varepsilon_{x y}$ distribution for various laminate patterns (@ bearing stress of $350 \mathrm{MPa}$ ).

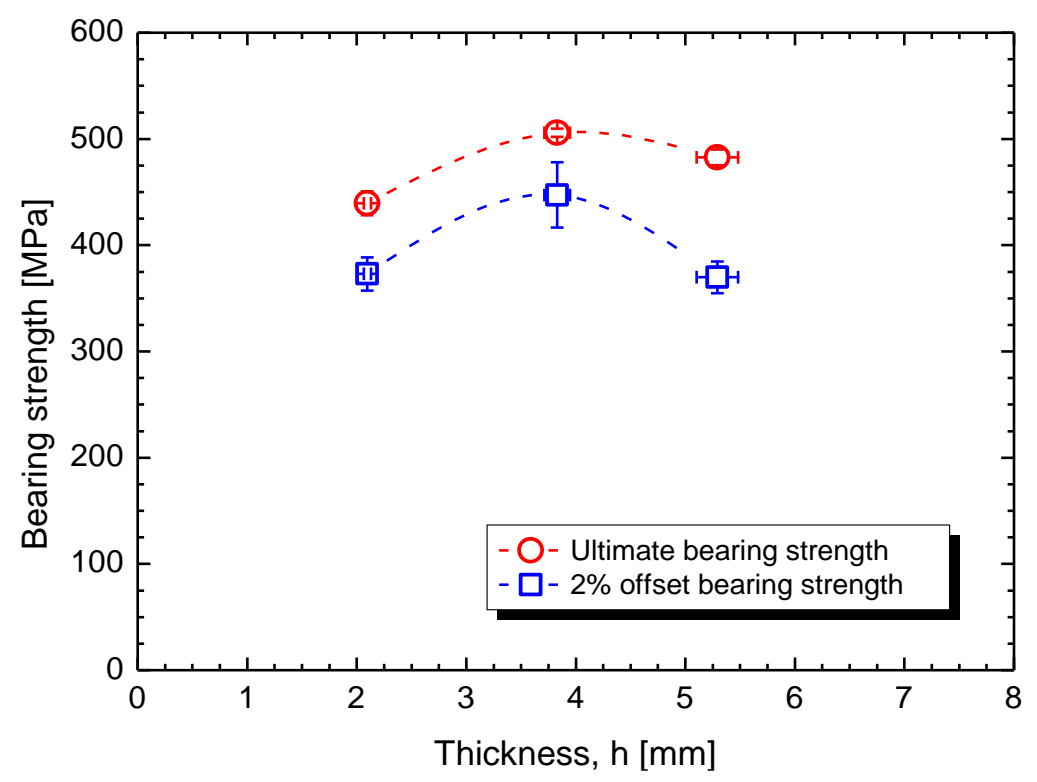

Figure 8. Effect of laminate thickness on $2 \%$ offset bearing strength and ultimate bearing strength $\left(\mathrm{D}=6 \mathrm{~mm}\right.$, layups $\left.=\left[0 /(45)_{2} / 0\right]_{\mathrm{sf}},\left[0 /(45)_{2} / 0\right]_{2 \mathrm{sf}},\left[0 /(45)_{2} / 0\right]_{3 \mathrm{sf}}\right)$.

According to Zhai et al. [20], out-of-plane displacement is referred to as secondary bending of single-lap joints due to the eccentric load path in the joints. Higher loading eccentricity can aggravate the tilt and bending of the bolt, making a smaller bolt-hole contact area and more concentrated load, and leading to the earlier occurrence of bearing 
damage as well as the premature bearing failure of the specimens. In general, the thinner the laminate, the lower out-of-plane displacement (higher bearing strength) due to the smaller loading eccentricity. As shown in Figure 9, the DIC results show that the thinnest laminate ( $2 \mathrm{~mm}$ thick) under a bolt torque of $2.2 \mathrm{Nm}$ exhibiting the lowest bearing strength has the highest out-of-plane displacement. Higher bolt torque may be required so that the thinnest laminate can achieve the highest bearing strength (lowest out-of-plane displacement). The $\sim 4 \mathrm{~mm}$ thick laminate exhibiting the highest bearing strength has the smallest out-of-plane displacement.

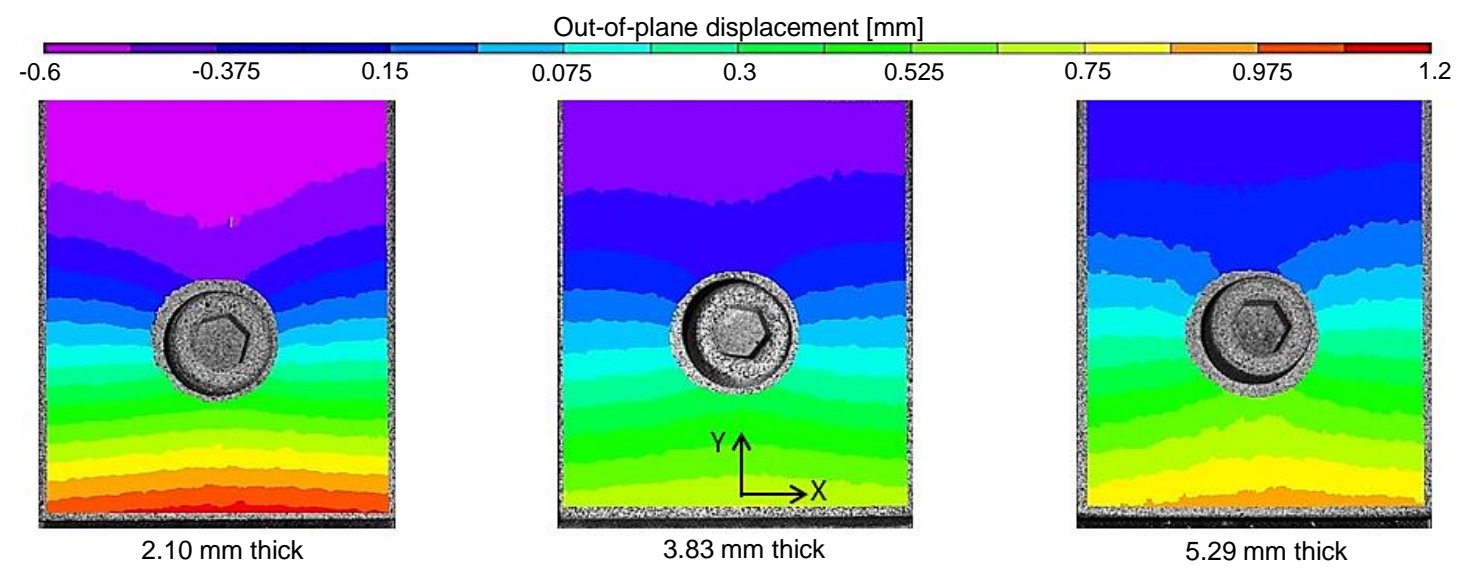

Figure 9. Out-of-plane deformation for various laminate thicknesses

(@ bearing stress of $350 \mathrm{MPa}$ ).

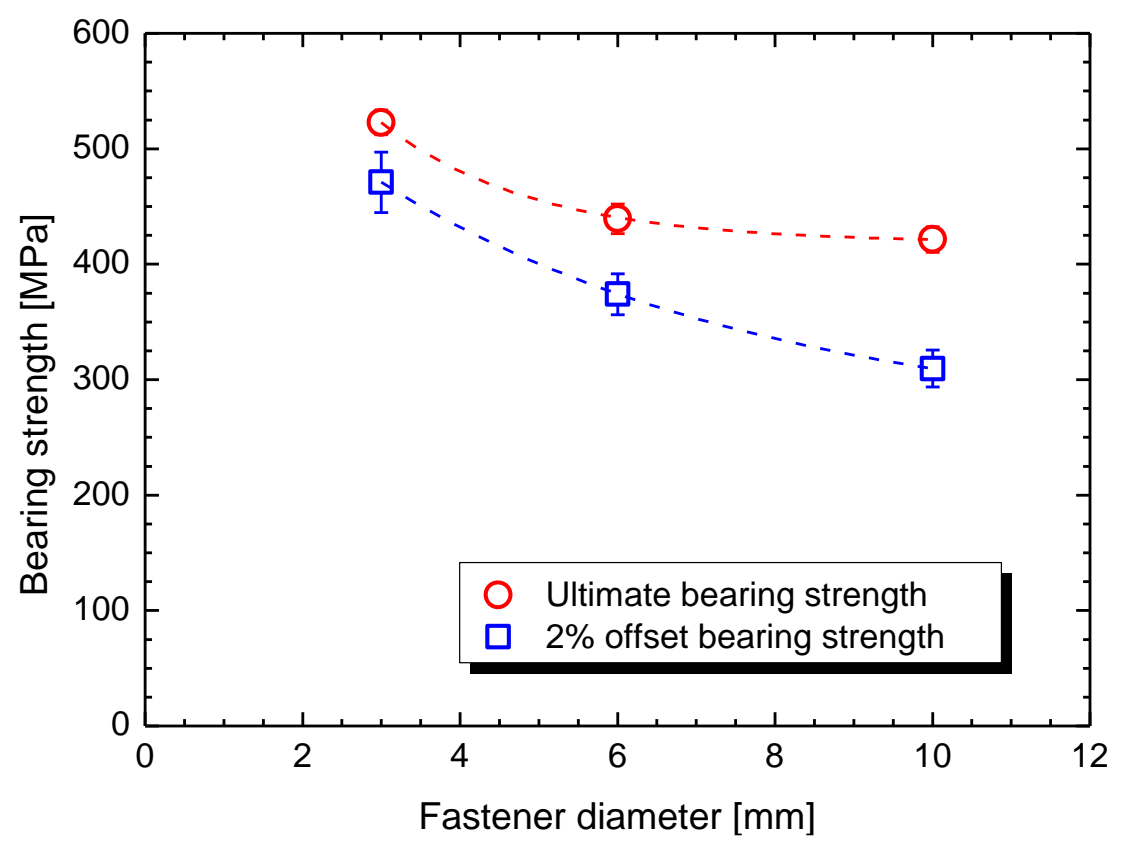

Figure 10. Effect of fastener size on $2 \%$ offset bearing strength and ultimate bearing strength (Layup $\left.=\left[0 /(45)_{2} / 0\right]_{\mathrm{sf}}\right)$.

\section{Effect of Fastener Size}

Three fastener sizes are considered: M3, M6, and M10. Figure 10 presents the effect of the fastener size on the ultimate and $2 \%$ offset bearing strengths. The bearing strengths 
decrease with increasing fastener diameter. This is because the bigger the bolt size, the larger the secondary bending due to bolt rotation and the lower the bearing strength. As shown in Figure 11, it is apparent that the out-of-plane displacement (secondary bending) increases with increasing bolt size.

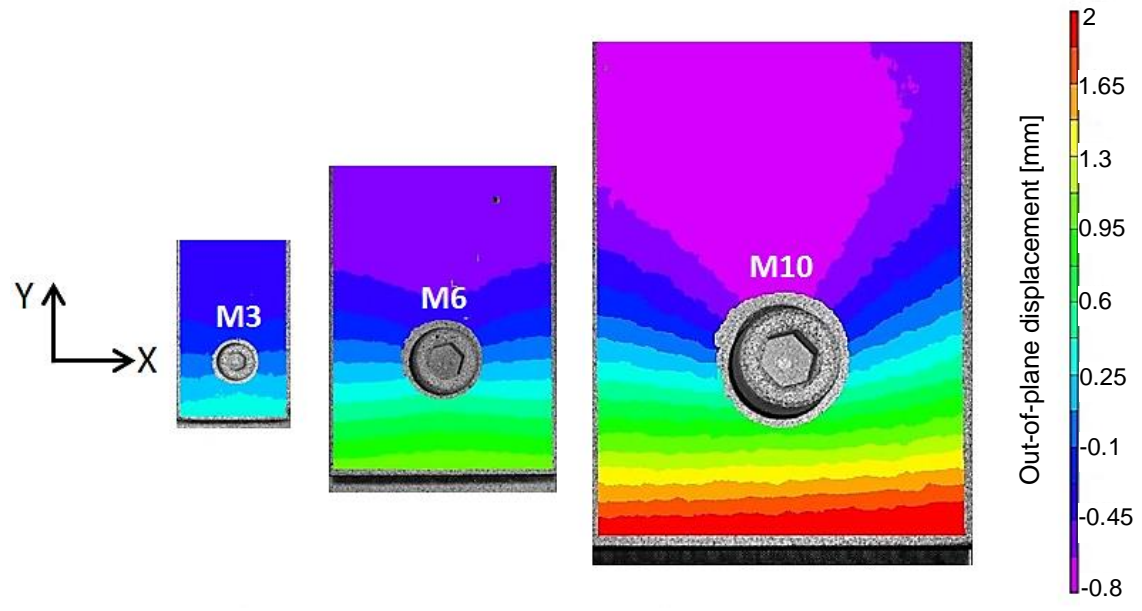

Figure 11. Out-of-plane deformation for various fastener sizes

(@ bearing stress of $350 \mathrm{MPa}$ ).

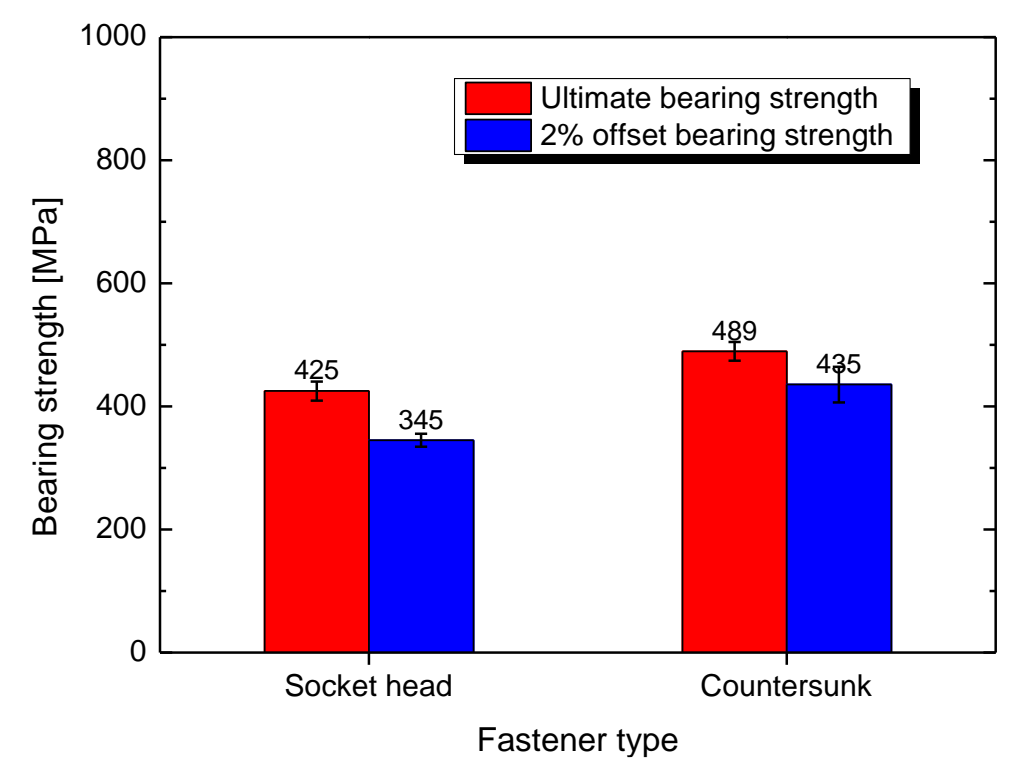

Figure 12. Effect of fastener type on $2 \%$ offset bearing strength and ultimate bearing strength $\left(\mathrm{D}=10 \mathrm{~mm}\right.$, layup $\left.=\left[0 /(45)_{2} / 0\right]_{4 \mathrm{sf}}, \mathrm{h}=7.17 \mathrm{~mm}\right)$.

\section{Effect of Fastener Type}

Figure 12 shows the effect of the fastener type on the ultimate and $2 \%$ offset bearing strengths. There are two types of fasteners investigated: socket head and countersunk. Under single shear loading (procedure B), the use of countersunk bolts does not decrease the bearing strengths. In fact, it provides a slight increase. This may be because the countersunk bolt can minimize the bolt-hole clearance and provide better clamping force compared to the socket head bolt resulting in slightly smaller secondary bending as shown in Figure 14. Moreover, from the strain contours (Figure 13), it is obvious that the countersunk bolt provides smaller strain concentrations compared to the socket head bolt. 


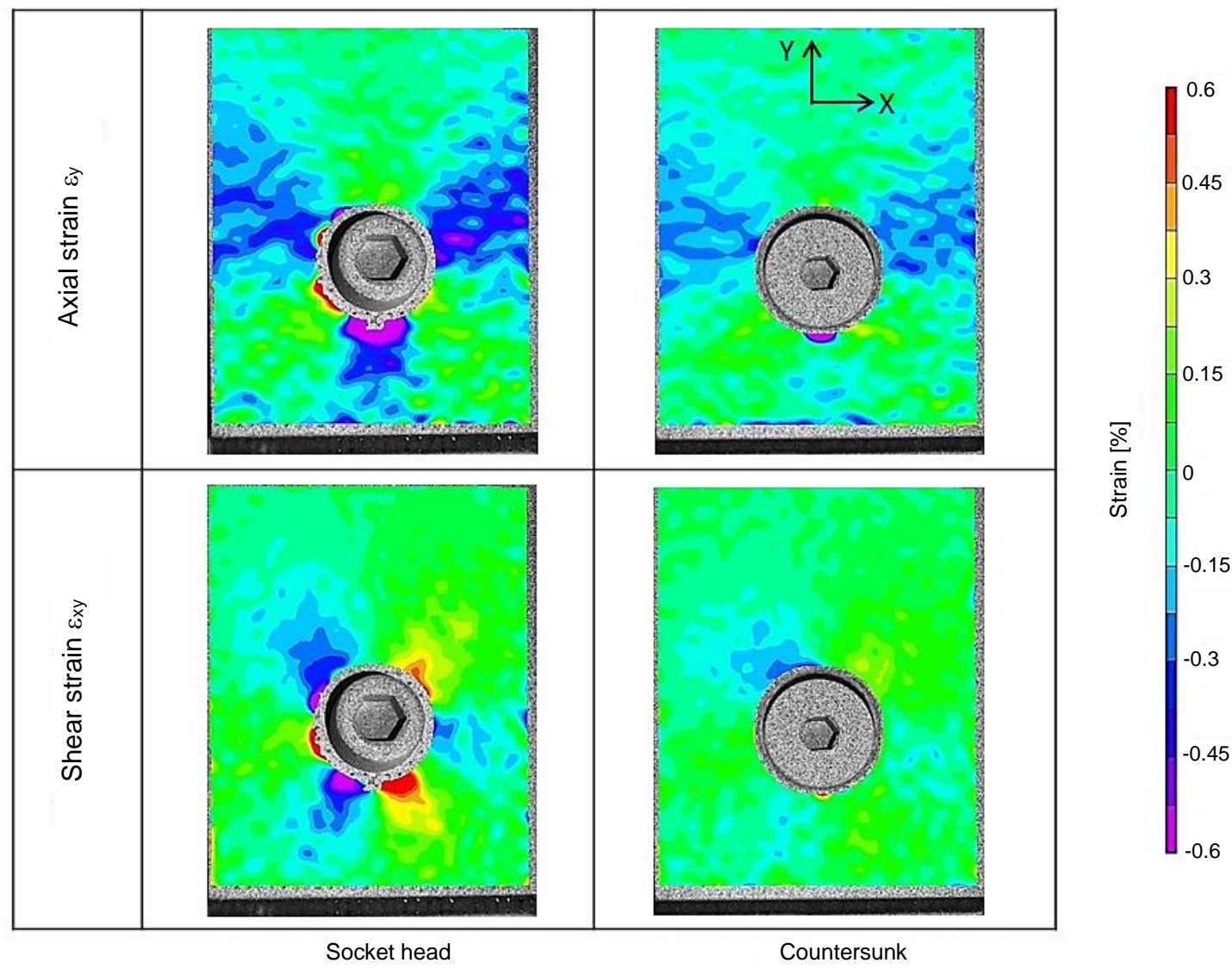

Figure 13. Axial strain $\varepsilon_{y}$ and shear strain $\varepsilon_{x y}$ distribution for different bolt types (@ bearing stress of $350 \mathrm{MPa}$ ).

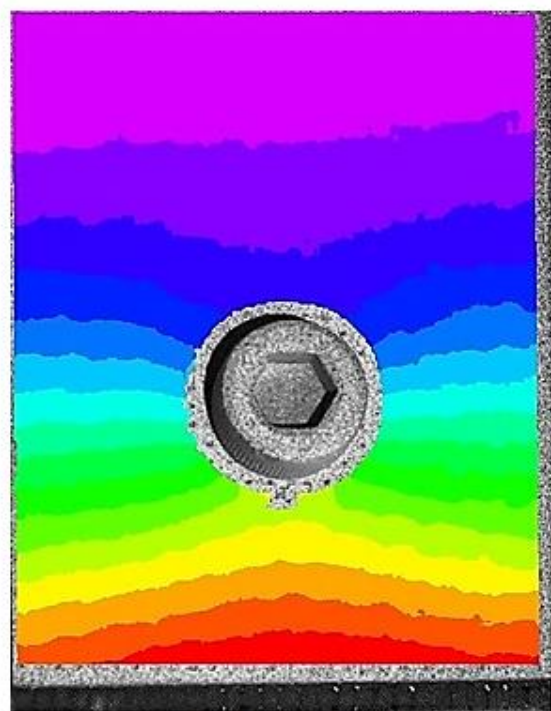

Socket head

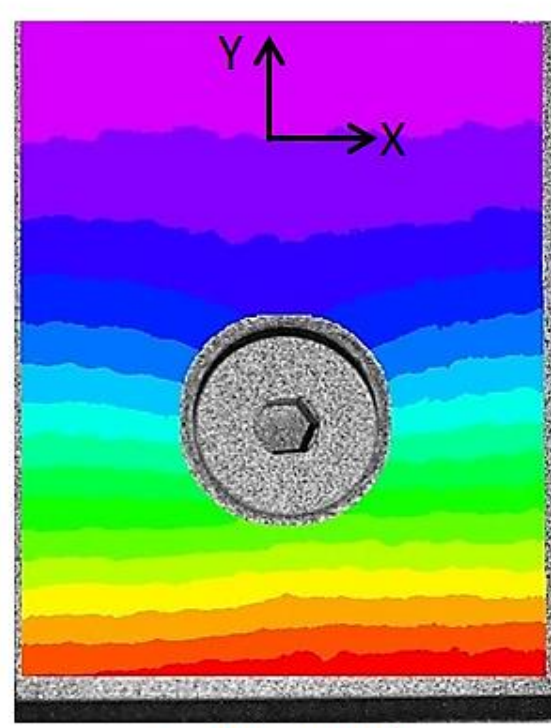

Countersunk :

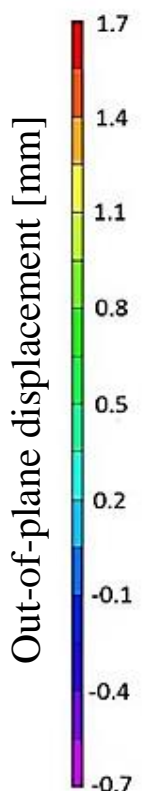

Figure 14. Out-of-plane deformation for different bolt types (@ bearing stress of $350 \mathrm{MPa}$ ). 


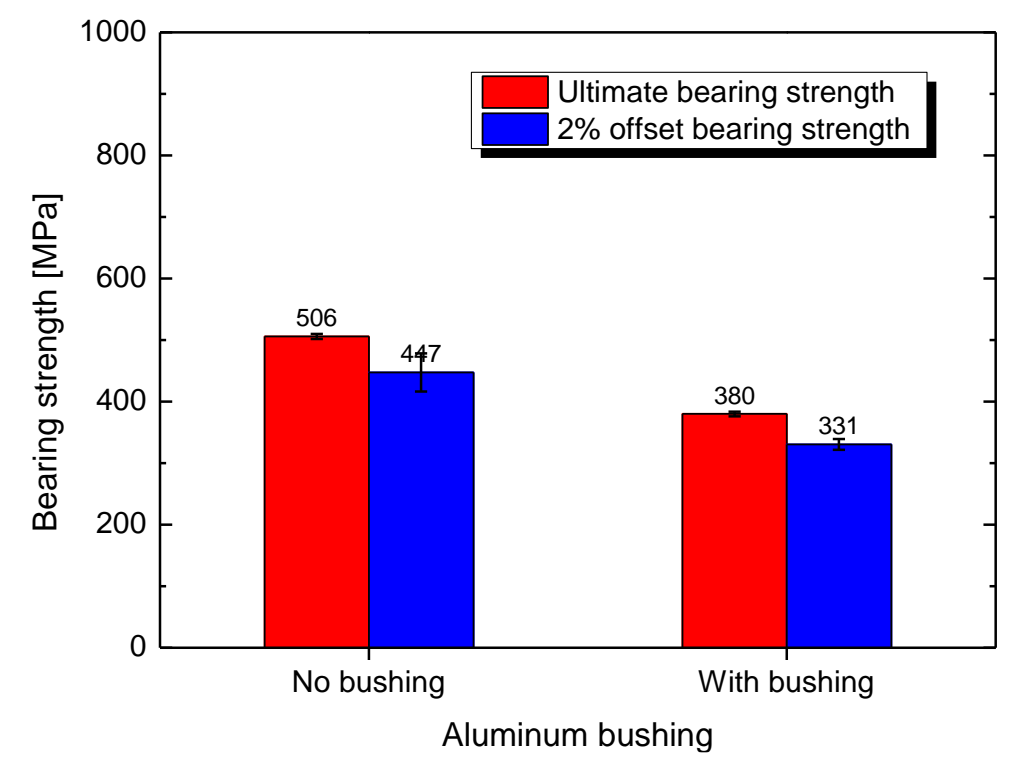

Figure 15. Effect of using bushing on $2 \%$ offset bearing strength and ultimate bearing strength $\left(\right.$ Layup $\left.=\left[0 /(45)_{2} / 0\right]_{2 s f}\right)$.

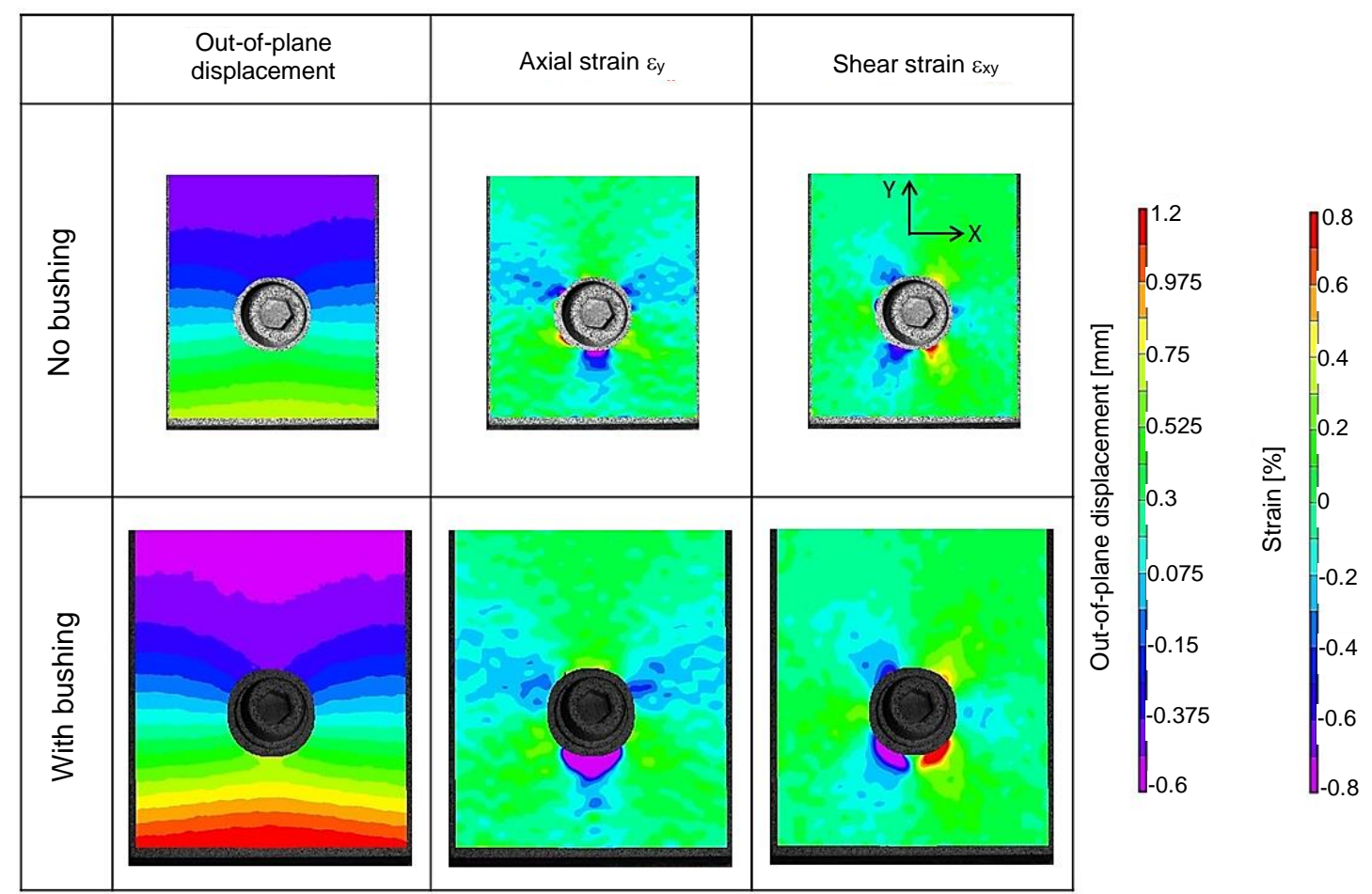

Figure 16. Out-of-plane deformation, axial strain $\varepsilon_{\mathrm{y}}$ and shear strain $\varepsilon_{\mathrm{xy}}$ distribution for with and without bushing (@ bearing stress of $350 \mathrm{MPa}$ ).

\section{Effect of Bushing}

Single top-hat type bushings were used and were made from Al6061-T6 with an inner diameter of $6 \mathrm{~mm}$ and an outer diameter of $8 \mathrm{~mm}$. The same fastener size of M6 was used for both with and without bushing cases. Figure 15 shows the effect of the use of bushing on the ultimate and $2 \%$ offset bearing strengths. It was observed that the use of the bushing reduces the bearing strengths. This effect is the same with the fastener size effect, 
i.e., the bigger the bolt size, the larger the secondary bending due to the bolt rotation and the lower the bearing strength. Here, the bushing can be thought of as a larger bolt. As shown in Figure 16, the DIC results show that the use of bushing increases the strain concentrations and the out-of-plane deformation (secondary bending) of the joints.

\section{CONCLUSIONS}

A commercial digital image correlation (DIC) system was utilized to experimentally study the progressive damage of composite fastened joints and to provide surface strain fields. Moreover, out-of-plane phenomena of joints due to the effect of laminate pattern, laminate thickness, fastener size, fastener type, and bushing were investigated.

It was found from DIC that:

1. The strain concentrations observed in the specimen can be used to identify fullfield damage onset and to monitor damage progression during loading.

2. The quasi isotropic laminate has the smallest axial compressive strain concentration and shear strain concentration providing the best bearing performance.

3. Under a bolt torque of $2.2 \mathrm{Nm}$, the $\sim 4 \mathrm{~mm}$ thick laminate exhibiting the highest bearing strength has the smallest out-of-plane displacement (secondary bending).

4. The out-of-plane displacement increases with increasing bolt size resulting in a decrease in bearing strength.

5. The countersunk bolt provides smaller out-of-plane displacement and strain concentrations compared to the socket head bolt resulting in slightly better bearing strength.

6. The use of aluminium single top-hat bushing reduces the bearing strength because it increases the out-of-plane deformation and strain concentrations of the joints.

These DIC results can potentially be used to develop and accurately validate numerical models.

\section{ACKNOWLEDGEMENTS}

The support through NUS competitive strategic grant no. R265000523646 is gratefully acknowledged.

\section{REFERENCES}

[1] Camanho PP, Lambert M. A design methodology for mechanically fastened joints in laminated composite materials. Composites Science and Technology. 2006;66:3004-20.

[2] Stickler P, Ramulu M. Experimental study of composite T-joints under tensile and shear loading. Advanced Composite Materials. 2006;15:193-210.

[3] Camanho PP, Matthews F. Stress analysis and strength prediction of mechanically fastened joints in FRP: a review. Composites Part A: Applied Science and Manufacturing. 1997;28:529-47.

[4] Hart-Smith L. Design and analysis of bolted and riveted joints in fibrous composite structures. Recent advances in structural joints and repairs for composite materials: Springer; 2003. p. 211-54. 
[5] Wor LC, Rahman MM. Stress behavior of tailor-welded blanks for dissimilar metals using finite element method. International Journal of Automotive and Mechanical Engineering. 2015;11:2541-54.

[6] Sivananth V, Vijayarangan S. Fatigue life analysis and optimization of a passenger car steering knuckle under operating conditions. International Journal of Automotive and Mechanical Engineering. 2015;11:2417-29.

[7] Peters W, Ranson W. Digital imaging techniques in experimental stress analysis. Optical engineering. 1982;21:213427--.

[8] Schreier H, Orteu JJ, Sutton MA. Image correlation for shape, motion and deformation measurements: Springer US; 2009.

[9] Yoneyama S, Murasawa G. Digital image correlation. Experimental Mechanics. 2009.

[10] Caminero M, Lopez-Pedrosa M, Pinna C, Soutis C. Damage monitoring and analysis of composite laminates with an open hole and adhesively bonded repairs using digital image correlation. Composites Part B: Engineering. 2013;53:76-91.

[11] Comer A, Katnam K, Stanley W, Young T. Characterising the behaviour of composite single lap bonded joints using digital image correlation. International Journal of Adhesion and Adhesives. 2013;40:215-23.

[12] Kumar RV, Bhat M, Murthy C. Experimental analysis of composite single-lap joints using digital image correlation and comparison with theoretical models. Journal of Reinforced Plastics and Composites. 2013;32:1858-76.

[13] Zhai Y, Li D, Li X, Wang L, Yin Y. An experimental study on the effect of bolthole clearance and bolt torque on single-lap, countersunk composite joints. Composite Structures. 2015;127:411-9.

[14] Dhôte J, Comer A, Stanley W, Young T. Study of the effect of liquid shim on single-lap joint using 3D Digital Image Correlation. Composite Structures. 2013;96:216-25.

[15] Egan B, McCarthy C, McCarthy M, Gray P, Frizzell R. Modelling a single-bolt countersunk composite joint using implicit and explicit finite element analysis. Computational Materials Science. 2012;64:203-8.

[16] Qing X, Sun H-T, Dagba L, Chang F-K. Damage-tolerance-based design of bolted composite joints. Composite Structures: Theory and Practice: ASTM International; 2001.

[17] Kelly D, Li R, Willgoss R, Crosky A. Improvement of bearing strength of mechanically fastened composite joints using fiber steering. International Sampe Symposium And Exhibition 2001. p. 415-26.

[18] Tong L. Bearing failure of composite bolted joints with non-uniform bolt-towasher clearance. Composites Part A: Applied Science and Manufacturing. 2000;31:609-15.

[19] Collings T. The strength of bolted joints in multi-directional CFRP laminates. Composites. 1977;8:43-55.

[20] Zhai Y, Li D, Li X, Wang L. An experimental study on the effect of joining interface condition on bearing response of single-lap, countersunk compositealuminum bolted joints. Composite Structures. 2015;134:190-8. 